\title{
Vascular endothelial growth factor polymorphisms as effect modifiers of oral squamous cell carcinoma risk: A systematic review and meta-analysis
}

\author{
CARMEN S. METZGER ${ }^{1}$, PEER W. KÄMMERER ${ }^{2}$, IRENE SCHMIDTMANN ${ }^{3}$ and JUERGEN BRIEGER ${ }^{1}$ \\ ${ }^{1}$ Department of Otorhinolaryngology, Head and Neck Surgery, Laboratory of Molecular Tumor Biology, \\ University Medical Center of the Johannes Gutenberg University, D-55101 Mainz, Rhineland-Palatinate; \\ ${ }^{2}$ Department of Oral, Maxillofacial and Plastic Surgery, University of Rostock, D-18057 Rostock, \\ Mecklenburg-Vorpommern; ${ }^{3}$ Institute of Medical Biostatistics, Epidemiology and Informatics (IMBEI), \\ University Medical Centre of the Johannes Gutenberg University, \\ D-55131 Mainz, Rhineland-Palatinate, Germany
}

Received September 30, 2014; Accepted October 3, 2014

DOI: $10.3892 / \mathrm{mco} .2014 .458$

\begin{abstract}
Smoking is one of the main risk factors for the development of oral squamous cell carcinoma (OSCC). Smoking may affect single-nucleotide polymorphism (SNP)-dependent vascular endothelial growth factor (VEGF)-induced angiogenic activity. Therefore, we systematically reviewed the published VEGF-SNP genotype data of OSCC patients and healthy individuals and performed a meta-analysis comparing the VEGF-SNP genotypes of smoking and non-smoking patients in association with OSCC incidence. Prospective and retrospective studies on the clinical comparison of OSCC patients with different VEGF-SNP genotypes were reviewed. The meta-analysis re-pooled studies of smoking and non-smoking OSCC patients with different VEGF-SNPs between 2006 and 2014. The identified articles were reviewed and those reporting pertinent information, assignment to smoking and non-smoking patient groups and sufficient data for estimation of an odds ratio (OR) with a $95 \%$ confidence interval (CI) were selected for the meta-analysis. Pooled ORs and CIs for the comparison of SNP distribution in the smoking and non-smoking subgroups were calculated and compared using the random-effects model. A total of 7 studies
\end{abstract}

Correspondence to: Professor Juergen Brieger, Department of Otorhinolaryngology, Head and Neck Surgery, Laboratory of Molecular Tumor Biology, University Medical Center of the Johannes Gutenberg University, 1 Langenbeckstrasse, D-55101 Mainz, Rhineland-Palatinate, Germany

E-mail: juergen.brieger@unimedizin-mainz.de

Abbreviations: OSCC, oral squamous cell carcinoma; SNP, single-nucleotide polymorphism; VEGF, vascular endothelial growth factor

Key words: oral squamous cell carcinoma, single-nucleotide polymorphisms, smoking, vascular endothelial growth factor, meta-analysis were included in the systematic review, which was followed by a meta-analysis using 3 pertinent studies. The reviewed studies reported discrepant findings, with differences between Asian and European patients. The meta-analysis demonstrated marginal but not statistically significant differences, suggesting that specific VEGF-SNPs may be OSCC risk modifiers for smokers, depending on the ethnic background. The performed meta-analysis suggested an increased OSCC risk for smokers carrying specific VEGF-genotypes, although the calculated data did not reach the level of significance. However, data have to be interpreted with caution due to the limited sample size. Therefore, further studies, including larger patient samples, are mandatory.

\section{Introduction}

Angiogenesis is a fundamental prerequisite for the development, growth and progression of solid malignant tumors, such as oral squamous cell carcinoma (OSCC) (1-3). The cytokine vascular endothelial growth factor (VEGF) is the most important regulator of tumor angiogenesis, is overexpressed in several tumor tissues and appears to be associated with the prognosis and outcome of various cancers $(4,5)$. Single-nucleotide polymorphisms (SNPs) within the VEGF gene are point mutations in the DNA sequence, partially associated with increased VEGF-levels; however, for the majority of SNPs the functional consequences remain unclear. SNPs may exhibit an interindividual variation in cancer risk and progression in various types of cancer, or a hypothetical association with treatment benefits. Various investigators reported that the effectiveness of modern combination therapies consisting of antiangiogenic and standard (chemo)therapy are dependent on VEGF gene and receptor polymorphisms, indicating the clinical relevance of these polymorphisms $(3,6-10)$. There is evidence regarding the involvement of the VEGF gene SNPs in OSCC development $(4,11)$, despite the fact that the number of available relevant studies is currently limited. Tobacco abuse is one of the main known risk factors for the 
deveopment of OSCC (12). Differences in recent studies may be attributed to the combination of a particular VEGF-SNP with environmental risk factors, such as cigarette smoking (13). In addition, a higher risk for urothelial carcinoma in cigarette smokers harbouring the high-risk VEGF genotypes was previously described (14) and it was hypothesized that smoking may impair VEGF-induced cell migration (15). Chen et al (16) demonstrated that the -2578 AA genotype decreased disease activity in rheumatoid arthritis in non-smokers, but lost its protective properties in smokers. In addition, the combination of smoking and the VEGF -2578 A-allele increased the risk of ischemic heart disease and myocardial infarction in patients with rheumatoid arthritis (17). Smokers with the VEGF $-460 \mathrm{C} / \mathrm{T}$ mutation exhibited a higher risk of esophageal adenocarcinoma compared to non-smokers (18). A possible association of smoking and VEGF-SNPs with the incidence of OSCC was investigated in single studies comprising only small samples. In brief, five common VEGF-SNPs in the 5'-untranslated promoter region [-2578 C/A, $-460 \mathrm{C} / \mathrm{T}$, $+405 \mathrm{C} / \mathrm{G}$ (also referred to as $-634 \mathrm{G} / \mathrm{C}$ ) and $-1154 \mathrm{G} / \mathrm{A}]$ or the 3 '-untranslated region $(+936 \mathrm{C} / \mathrm{T})$ and their association with OSCC were analysed (6,19-22). Studies investigating VEGF-SNPs and their correlation with OSCC were reviewed. In order to obtain data supporting an association between cigarette smoking and specific VEGF-SNPs as risk modifiers in OSCC, adequate data were pooled and a meta-analysis was conducted.

\section{Materials and methods}

Search strategy and study selection criteria. We conducted a systematic review of all available published studies investigating the association between the genetic variations of the VEGF gene and OSCC. We identified studies by a literature search of PubMed and ScienceDirect (1980 through to September 20,2014) using the following heading terms and/or text words: 'vascular endothelial growth factor', 'VEGF', 'smoking', 'oral' and 'polymorphism' in different combinations. All published articles were retrieved and their bibliographies were searched to identify additional relevant publications. The identified studies were assessed based on original data analysis to determine their eligibility for inclusion in a quantitative analysis. Patient genotypes in association with smoking habits were analysed in a meta-analysis. The systematic review and the following meta-analysis included studies fulfilling the following inclusion criteria: i) only studies published in English; and ii) only human cohort or case-control studies (meta-analyses, reviews and studies with overlapping patient cohorts were excluded). Additionally, for the meta-analysis i) only VEGF-SNPs investigated by at least two research groups; and ii) only studies with separate genotype distribution for smokers and non-smokers were included; iii) only VEGF-SNPs investigated by at least two research groups; and iv) only studies with separate genotype distribution for smokers and non-smokers.

Data extraction. The full-text articles were reviewed to determine their eligibility according to the abovementioned inclusion criteria and relevant data were independently extracted and tabulated. The following characteristics were

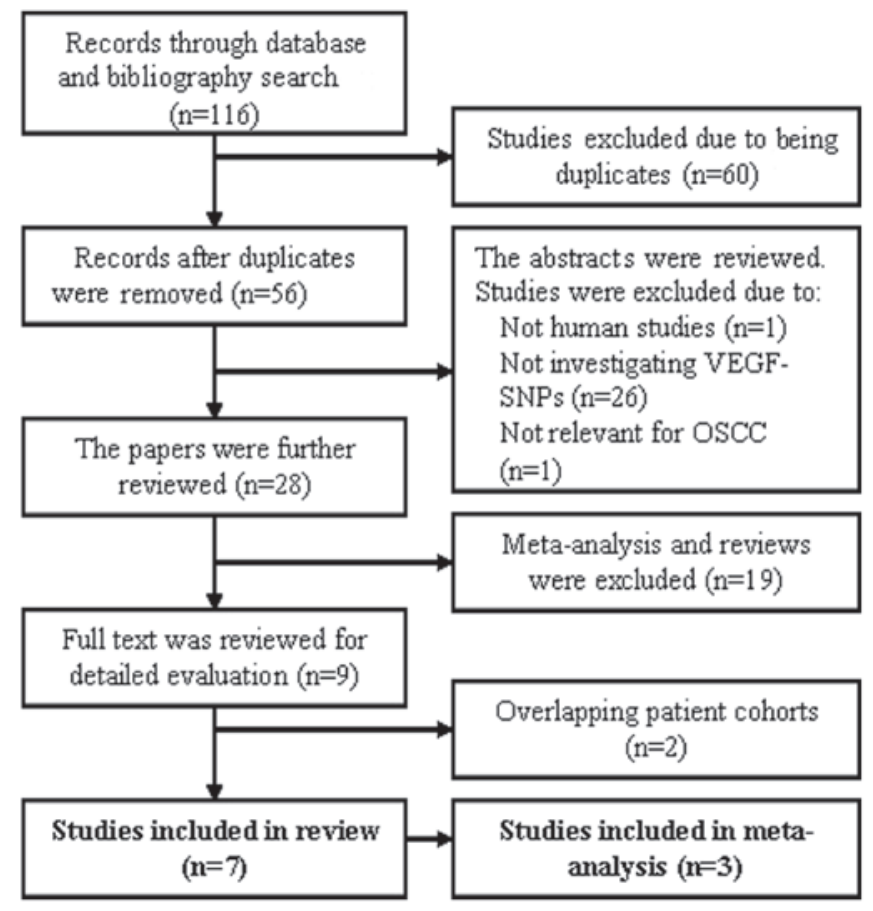

Figure 1. Flowchart of the study selection process for the meta-analysis and systematic review. VEGF, vascular endothelial growth factor; SNPs, single-nucleotide polymorphisms; OSCC, oral squamous cell carcinoma.

collected for each study: the first author's surname, year of publication, country of origin, ethnicity, gender and number of study subjects, smoking status, SNP genotyping method and genotype frequencies in the smoking and non-smoking subgroups.

Statistical analysis. For the meta-analysis, we abstracted the observed genotypes divided in smoking and non-smoking subgroups. The odds ratios (ORs) and asymptotic 95\% confidence intervals (CIs) were determined to assess the association between the relevant VEGF-SNPs and the smoking habits of the OSCC patients in comparison with the dominant homozygous genotype. The ORs were calculated by use of the assumptions of a random-effects model, which incorporates between-study heterogeneity. We estimated pooled ORs and corresponding 95\% CIs for the included studies. Heterogeneity among the studies was assessed using a $\chi^{2}$ statistic and the $\mathrm{I}^{2}$ statistic. The calculation of the values and the forest plots illustrating study-specific ORs were performed using Review Manager software, version 5.2.11 (The Nordic Cochrane Centre, The Cochrane Collaboration). No correction for multiple testing was applied, i.e., only the error rate per comparison was controlled. Statistical analyses were performed using a two-sided $\mathrm{z}$ test. $\mathrm{P}<0.05$ was considered to indicate statistically significant differences. All the statistical tests were two-sided.

\section{Results}

Search results. A total of 116 studies were identified using the abovementioned search terms and 7 studies met the inclusion criteria for a review, as outlined by the flowchart in Fig. 1. The studies (Table I) were further reviewed and assessed with respect to their eligibility for inclusion in a meta-analysis 
Table I. Studies included in the systematic review investigating the association of the VEGF-SNPs +405 C/G, -1154 G/A, -2578 $\mathrm{C} / \mathrm{A}$ and $+936 \mathrm{C} / \mathrm{T}$ with OSCC.

\begin{tabular}{|c|c|c|c|c|c|c|}
\hline SNP & Name & Ethnicity & Cases & Method & First author (refs.) & Year \\
\hline \multirow[t]{2}{*}{ rs2010963 } & \multirow[t]{2}{*}{$+405 \mathrm{C} / \mathrm{G}$} & Caucasian & 113 & PCR & Kämmerer et al (19) & 2013 \\
\hline & & Caucasian & 114 & PCR & Supic et al (20) & 2012 \\
\hline \multirow[t]{2}{*}{ rs 1570360} & \multirow[t]{2}{*}{$-1154 \mathrm{G} / \mathrm{A}$} & Caucasian & 113 & PCR & Kämmerer et al (19) & 2013 \\
\hline & & Caucasian & 114 & PCR & Supic et al (20) & 2012 \\
\hline \multirow[t]{5}{*}{ rs3025039 } & \multirow[t]{5}{*}{ +936 C/T } & Caucasian & 113 & PCR & Kämmerer et al (19) & 2013 \\
\hline & & Caucasian & 114 & PCR & Supic et al (20) & 2012 \\
\hline & & Caucasian & 144 & PCR-RFLP & Yapijakis et al (6) & 2007 \\
\hline & & Asian & 295 & PCR-RFLP & Lin et al (24) & 2012 \\
\hline & & Asian & 218 & PCR-RFLP & Cheng et al (23) & 2008 \\
\hline \multirow[t]{2}{*}{ rs699947 } & \multirow[t]{2}{*}{$-2578 \mathrm{C} / \mathrm{A}$} & Caucasian & 113 & PCR & Kämmerer et al (19) & 2013 \\
\hline & & Caucasian & 114 & PCR & Supic et al (20) & 2012 \\
\hline \multirow[t]{3}{*}{ rs833061 } & \multirow[t]{3}{*}{$-460 \mathrm{C} / \mathrm{T}$} & Caucasian & 113 & PCR & Kämmerer et al (19) & 2013 \\
\hline & & Asian & 137 & PCR & $\mathrm{Ku}$ et al (21) & 2005 \\
\hline & & Asian & 80 & PCR-RFLP & Borase et al (25) & 2014 \\
\hline
\end{tabular}

VEGF, vascular endothelial growth factor; SNPs, single-nucleotide polymorphisms; OSCC, oral squamous cell carcinoma; PCR, polymerase chain reaction; RFLP, restriction fragment length polymorphism.

investigating the association between OSCC and VEGF-SNPs in connection with smoking. The sample size of the studies ranged between 80-295 patients and 80-331 controls. Three of the study cohorts were European and the remaining cohorts were Asian. The studies identified for the meta-analysis investigated five different VEGF-SNPs and the association with the smoking habits of the OSCC patients between 1992 and 2009. Only four SNPs (+405 C/G, -2578 C/A, +936 C/T and $-1154 \mathrm{G} / \mathrm{A})$ were investigated by at least two research groups. The characteristics of the studies included in the meta-analysis are summarized in Table II.

Quantitative summary. Our literature research identified 7 studies investigating VEGF-SNP genotypes in OSCC patients aged 49-62 years. The majority of the patients in the overall sample were male, whereas in only 2 of the studies the genders were almost equally distributed. Cheng et al (23) observed no significant difference in genotype, phenotype or gene frequency between the OSCC and control groups and merely suggested an association of the $+936 \mathrm{C}$ allele with vascular invasion in OSCC. In agreement with this study, Lin et al (24) did not identify a correlation with the incidence of oral cancer or poor disease-free survival. By contrast, in the European cohorts, such an association was observed. Yapijakis et al (6) demonstrated that the low expression of the $+936 \mathrm{~T}$ allele was significantly increased in the patient group. In addition, the $+936 \mathrm{CC}$ genotype was associated with advanced OSCC in the study by Supic et al (20). An additional European study did not identify any association of the $+936 \mathrm{C} / \mathrm{T}$ polymorphism with OSCC (19). Two Asian studies suggested SNP $-460 \mathrm{C} / \mathrm{T}$ as a suitable genetic marker of OSCC $(21,25)$, whereas in a European study no such association was observed (19), indicating an effect of the origin of the subjects. Kämmerer et al (19) identified the -405 GG genotype as a biomarker for poor survival in advanced OSCC. Supic et al (20) reported decreased overall survival associated with SNP -1154 GG, suggesting a consideration of this SNP as a prognostic marker of poor survival in advanced-stage OSCC patients. Kämmerer et al (19) observed a worse overall and disease-free survival for advanced OSCC associated with the -1154 AA genotype. Despite the differences attributed to genetic background, environmental factors such as smoking or alcohol consumption were proven to be the main risk factors for the development of OSCC. Genetic susceptibility and the potential interaction of haplotype and smoking status were suggested. In the included studies, $67.3-95.8 \%$ of the participants were smokers. On investigating the VEGF-SNP-2578 AC, Kämmerer et al (19) demonstrated significant evidence of an increased OSCC incidence among smokers carrying this SNP, whereas Supic et al (20) did not observe such an association. Yapijakis et al (6) reported that the +936 T-allele was associated with an increased OSCC risk in smokers. As regards the VEGF-SNPs $-1158 \mathrm{~A} / \mathrm{G}$ and $+405 \mathrm{C} / \mathrm{G}$, there was no evidence reported by the analysed studies supporting an association of smoking and these VEGF-SNPs with OSCC.

To further substantiate the observations regarding the association of smoking with the VEGF-SNP genotypes of OSCC patients, we performed a meta-analysis of 3 studies including cohorts of 113-144 OSCC patients.

Quantitative analysis (meta-analysis). A total of 3 articles provided sufficient information and were included in a meta-analysis. We reanalysed the ORs and the $95 \%$ CIs of the single studies to assess comparability prior to pooling the genotype distribution of the smoking and non-smoking subgroups, performing a pooled reanalysis. By merging the study results we were able to increase the samples to $373 \mathrm{OSCC}$ patients for the $-2578 \mathrm{C} / \mathrm{A}$ and 227 patients for the $+405 \mathrm{C} / \mathrm{G},+936 \mathrm{C} / \mathrm{T}$ 
Table II. Characteristics of included studies investigating the association of the VEGF-SNPs +405C/G, -1154 G/A, $-2578 \mathrm{C} / \mathrm{A}$ and $+936 \mathrm{C} / \mathrm{T}$ with the smoking status of OSCC patients.

\begin{tabular}{|c|c|c|c|c|c|c|c|c|c|}
\hline SNP & Name & $\begin{array}{l}\text { Ethnicity } \\
\text { (country } \\
\text { of origin) }\end{array}$ & Case diagnosis & Cases & $\begin{array}{l}\text { Gender } \\
\text { (male/ } \\
\text { female) }\end{array}$ & $\begin{array}{c}\text { Smokers/ } \\
\text { non- } \\
\text { smokers }\end{array}$ & Method & First author (refs.) & Year \\
\hline \multirow[t]{2}{*}{ rs2010963 } & $+405 \mathrm{C} / \mathrm{G}$ & $\begin{array}{l}\text { Caucasian } \\
\text { (Germany) }\end{array}$ & Histopathologically & 113 & $60 / 53$ & $76 / 37$ & PCR & Kämmerer et al (19) & 2013 \\
\hline & & $\begin{array}{l}\text { Caucasian } \\
\text { (Serbia) }\end{array}$ & Histopathologically & 114 & $84 / 30$ & $96 / 18$ & PCR & Supic et al (20) & 2012 \\
\hline \multirow[t]{2}{*}{ rs 1570360} & $-1154 \mathrm{G} / \mathrm{A}$ & $\begin{array}{l}\text { Caucasian } \\
\text { (Germany) }\end{array}$ & Histopathologically & 113 & $60 / 53$ & $76 / 37$ & PCR & Kämmerer et al (19) & 2013 \\
\hline & & $\begin{array}{l}\text { Caucasian } \\
\text { (Serbia) }\end{array}$ & Histopathologically & 114 & $84 / 30$ & $96 / 18$ & PCR & Supic et al (20) & 2012 \\
\hline \multirow[t]{3}{*}{ rs3025039 } & $+936 \mathrm{C} / \mathrm{T}$ & $\begin{array}{l}\text { Caucasian } \\
\text { (Germany) }\end{array}$ & Histopathologically & 113 & $60 / 53$ & $76 / 37$ & PCR & Kämmerer et al (19) & 2013 \\
\hline & & $\begin{array}{l}\text { Caucasian } \\
\text { (Serbia) }\end{array}$ & Histopathologically & 114 & $84 / 30$ & $96 / 18$ & PCR & Supic et al (20) & 2012 \\
\hline & & $\begin{array}{l}\text { Caucasian } \\
\text { (Germany/ } \\
\text { Greece) }\end{array}$ & Histopathologically & 144 & $116 / 18$ & $138 / 6$ & $\begin{array}{l}\text { PCR- } \\
\text { RFLP }\end{array}$ & Yapijakis et al (6) & 2007 \\
\hline \multirow[t]{2}{*}{ rs699947 } & $-2578 \mathrm{C} / \mathrm{A}$ & $\begin{array}{l}\text { Caucasian } \\
\text { (Germany) }\end{array}$ & Histopathologically & 113 & $60 / 53$ & $76 / 37$ & PCR & Kämmerer et al (19) & 2013 \\
\hline & & $\begin{array}{l}\text { Caucasian } \\
\text { (Serbia) }\end{array}$ & Histopathologically & 114 & $84 / 30$ & $96 / 18$ & PCR & Supic et al (20) & 2012 \\
\hline
\end{tabular}

VEGF, vascular endothelial growth factor; SNPs, single-nucleotide polymorphisms; OSCC, oral squamous cell carcinoma; PCR, polymerase chain reaction; RFLP, restriction fragment length polymorphism.

and -1154 G/A VEGF-SNPs. The reanalysed ORs, 95\% CIs and forest plots of the single studies and the pooled data are shown in Fig. 2.

Overall, we could not identify any significant association between the investigated SNPs $-2578 \mathrm{~A} / \mathrm{C},+936 \mathrm{C} / \mathrm{T}$ and $+405 \mathrm{C} / \mathrm{G}$ and the smoking habits of the OSCC patients comparing the heterozygote genotype $(+405 \mathrm{CG}$ vs. CC: $\mathrm{OR}=1.39,95 \% \mathrm{CI}: 0.31-6.24, \mathrm{P}=0.67 ;+936 \mathrm{CT}$ vs. $\mathrm{CC}: \mathrm{OR}=0.62$, 95\% CI: $0.33-1.15, \mathrm{P}=0.13$; -1154 AG vs. $\mathrm{GG}: \mathrm{OR}=0.67$, 95\% CI: $0.34-1.32, \mathrm{P}=0.24 ;-2578$ AC vs. $\mathrm{CC}: \mathrm{OR}=0.85$, 95\% CI: $0.37-1.95, \mathrm{P}=0.71)$; or the infrequent homozygote genotype (+405 GG vs. CC: $\mathrm{OR}=1.61,95 \% \mathrm{CI}: 0.40-6.53$, $\mathrm{P}=0.50 ;+936$ TT vs. $\mathrm{CC}: \mathrm{OR}=0.54,95 \%$ CI: $0.12-2.49, \mathrm{P}=0.22$; -1154 AA vs. $\mathrm{GG}: \mathrm{OR}=0.45,95 \% \mathrm{CI}: 0.06-3.59, \mathrm{P}=0.45$; -2578 AA vs. $\mathrm{CC}$ : $\mathrm{OR}=0.52,95 \% \mathrm{CI}$ : $0.05-5.71, \mathrm{P}=0.59)$ with the dominant homozygote genotype.

\section{Discussion}

In this review of the literature and subsequent meta-analysis we evaluated a possible association of specific VEGF-SNPs and OSCC, with a focus on the correlation of specific VEGF-SNPS and smoking with cancer risk.

The published results on the $+936 \mathrm{C} / \mathrm{T}$ VEGF-SNP have been inconsistent, possibly due to the differences in cohort origin. The investigated Asian cohorts suggested a correlation between the +936 C-allele and vascular invasion. Accordingly, the European cohort exhibited a significant increase in the frequency of the +936 T-allele in the smoking patient group. Although 3 studies of European origin were pooled in this meta-analysis, a final conclusion regarding the association of smoking with the $+936 \mathrm{C} / \mathrm{T}$ genotype could not be drawn, due to the limited number of patients. In a study investigating the +936 C/T VEGF-SNP in breast cancer, the +936 T-allele was less frequently detected in breast cancer patients compared to healthy subjects, indicating a protective role of this genetic variant $(1,26)$. However, another published study suggested there was no association between the SNP +936 C/T and breast cancer risk (27). Of note, the comparison between OSCC and breast cancer may be difficult, as breast cancer studies did not investigate the correlation with the smoking habits of the patients.

In the context of the performed meta-analysis, we could not identify an increased likelihood for smoking OSCC patients carrying a specific $-1154 \mathrm{G} / \mathrm{A}$ genotype. In contrast to OSCC, other cancer types, such as breast cancer, have been more extensively investigated, as indicated by the number of available studies $(1,26,27)$. Furthermore, patients carrying the AA genotype exhibited a decreased prostate cancer risk (28) and less advanced melanomas (29) compared to patients with other genotypes.

Observations on SNP -460 C/T indicated an effect on OSCC and suggested that it may be a suitable genetic marker when considering the Asian studies, whereas in the European 


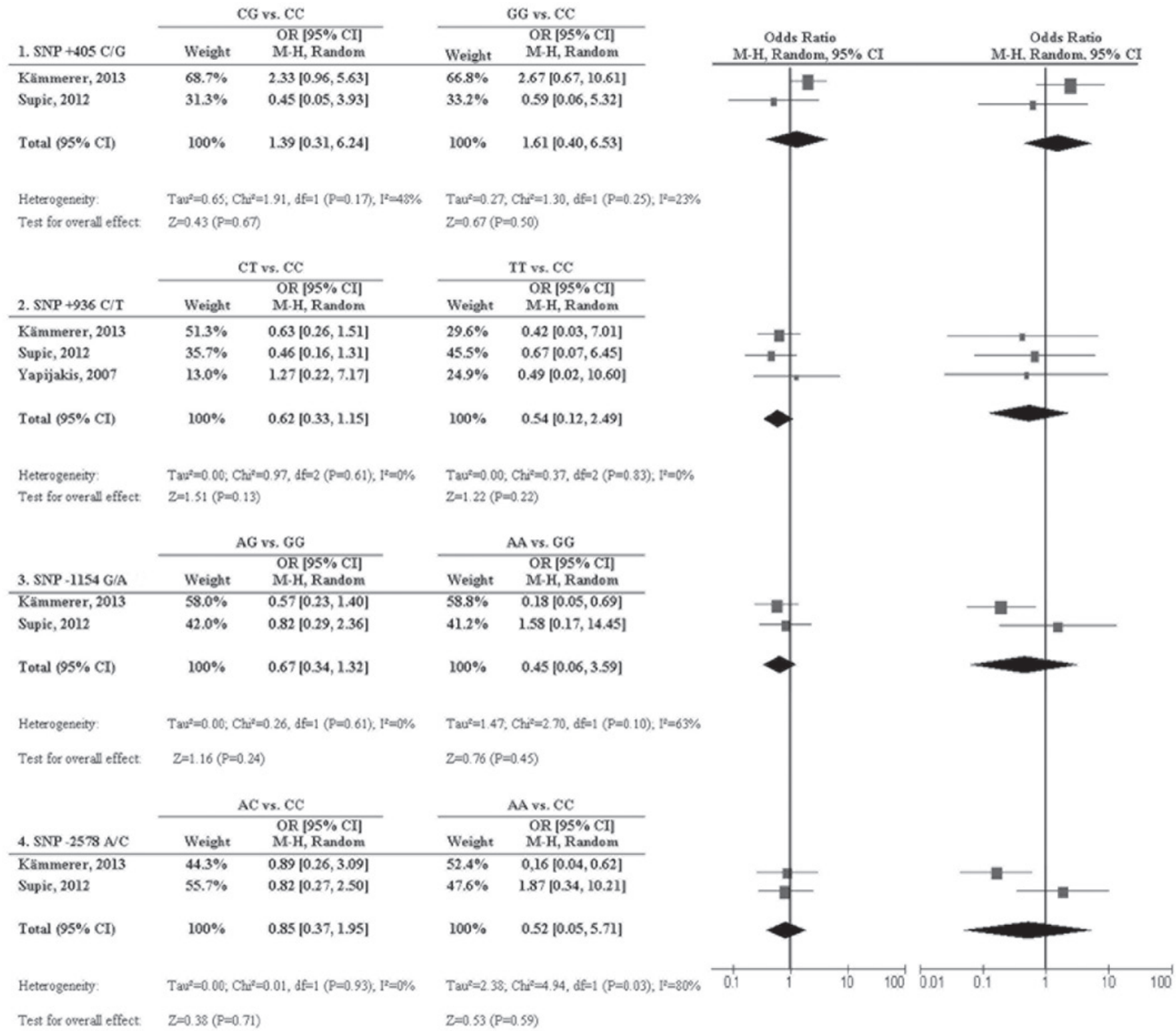

Figure 2. Forest plot of ORs for the association of the $-460 \mathrm{C} / \mathrm{G},+936 \mathrm{C} / \mathrm{T},-1154 \mathrm{G} / \mathrm{A}$ and $-2578 \mathrm{C} / \mathrm{A}$ SNPs in the vascular endothelial growth factor gene, with susceptibility to oral squamous cell carcinoma and smoking status. OR, odds ratio; CI, confidence interval; SNP, single-nucleotide polymorphism.

cohorts no such association was observed. The studies included in the systematic review yielded inconsistent results, possibly due to genetic heterogeneity of different ethnicities.

A study investigating the promoter SNP -2578 C/A provided evidence supporting an association with the development of atherosclerosis. Howell et al (10) observed a protective role of the $\mathrm{CC}$ genotype, whereas AA was associated with an increased risk of atherosclerosis. Analysing a potential association of this SNP and the smoking behavior of the patients provided evidence of a strong interaction in patients with rheumatoid athritis for ischemic heart diseases and/or myocardial infarction (17). Lin et al (22) performed a meta-analysis on lung cancer patients among smokers. The VEGF-SNP -2578 A was associated with an increased risk of lung cancer, suggesting that this polymorphism may not be an independent risk factor. The authors hypothesized a potential role of the -2578 A allele as effect modifier increasing lung cancer risk synergistically with smoking, a mechanism also potentially relevant in OSCC.
We could not confirm an increased OSCC risk with respect to the VEGF-promoter SNP +405 C/G, which was in accordance to the results of a previous study investigating lung cancer, which did not indicate any such association, despite stratification by ethnicity, smoking status or histological type (22).

A previous study investigating the association between VEGF-SNPs and rheumatoid arthritis suggested a decreased disease activity in patients carrying the haplotype $-2578 \mathrm{~A} /-460 \mathrm{C} /+405 \mathrm{G}$ in never-smokers (16). This observation increased the evidence of a linkage disequilibrium.

The discrepancy of the findings between the single studies may be partially explained by the relatively small study groups and the different ethnic backgrounds of the patients, variable gender composition and unknown lifestyles and gene-environment interactions. The present meta-analysis was further limited by the relatively limited number of studies investigating the VEGF-SNPs in OSCC. In addition, the result variability may be attributed to the cumulative effects 
of cigarette smoke components. For example, while $\mathrm{CO}$ has been shown to destabilize HIF-1 $\alpha$ and suppress target genes such as VEGF, nicotine was shown to promote angiogenesis and induce the expression of the VEGF gene (30). Cigarette smoke consists of 4,000 compounds, making the observation of the cumulative mechanism of the VEGF regulation more complex (31).

In summary, the reviewed studies suggest effects of single VEGF polymorphisms alone, in combination, or by interaction with environmental factors on the tumour characteristics. It may be concluded that, although the data of the available studies were pooled and reanalysed during the meta-analysis, the investigated patient samples remain insufficient to establish a definitive association of specific VEGF-SNPs with the smoking habit of OSCC patients. Therefore, a large epidemiological study must be undertaken to verify the clinical relevance of these VEGF-SNPs.

\section{References}

1. Kataoka N, Cai Q, Wen W, Shu XO, Jin F, Gao YT and Zheng W: Population-based case-control study of VEGF gene polymorphisms and breast cancer risk among Chinese women. Cancer Epidemiol Biomarkers Prev 15: 1148-1152, 2006.

2. Folkman J, Merler E, Abernathy C and Williams G: Isolation of a tumor factor responsible for angiogenesis. J Exp Med 133: 275-288, 1971.

3. Renner W, Kotschan S, Hoffmann C, Obermayer-Pietsch B and Pilger E: A common $936 \mathrm{C} / \mathrm{T}$ mutation in the gene for vascular endothelial growth factor is associated with vascular endothelial growth factor plasma levels. J Vasc Res 37: 443-448, 2000.

4. Johnstone S and Logan RM: Expression of vascular endothelial growth factor (VEGF) in normal oral mucosa, oral dysplasia and oral squamous cell carcinoma. Int J Oral Maxillofac Surg 36: 263-266, 2007.

5. Li C, Shintani S, Terakado N, Klosek SK, Ishikawa T, Nakashiro $\mathrm{K}$ and Hamakawa $\mathrm{H}$ : Microvessel density and expression of vascular endothelial growth factor, basic fibroblast growth factor, and platelet-derived endothelial growth factor in oral squamous cell carcinomas. Int J Oral Maxillofac Surg 34: 559-565, 2005.

6. Yapijakis C, Vairaktaris E, Vassiliou S, et al: The low VEGF production allele of the $+936 \mathrm{C} / \mathrm{T}$ polymorphism is strongly associated with increased risk for oral cancer. J Cancer Res Clin Oncol 133: 787-791, 2007.

7. Schneider BP, Radovich M and Miller KD: The role of vascular endothelial growth factor genetic variability in cancer. Clin Cancer Res 15: 5297-5302, 2009.

8. Schneider BP, Wang M, Radovich M, et al: Association of vascular endothelial growth factor and vascular endothelial growth factor receptor-2 genetic polymorphisms with outcome in a trial of paclitaxel compared with paclitaxel plus bevacizumab in advanced breast cancer: ECOG 2100. J Clin Oncol 26: 4672-4678, 2008.

9. Mohammadi M, Bazrafshani MR, Day PJ, et al: Vascular endothelial growth factor production is regulated by gene polymorphisms. Iran J Immunol 6: 119-129, 2009.

10. Howell WM, Ali S, Rose-Zerilli MJ and Ye S: VEGF polymorphisms and severity of atherosclerosis. J Med Genet 42: 485-490, 2005.

11. Mărgăritescu C, Pirici D, Stîngă A, Simionescu C, Raica M, Mogoantă L, Stepan A and Ribatti D: VEGF expression and angiogenesis in oral squamous cell carcinoma: an immunohistochemical and morphometric study. Clin Exp Med 10: 209-214, 2010.

12. World Health Organisation: Global data on incidence of oral cancer. http://www.who.int/oral_health/publications/oral_ cancer_brochure.pdf?ua=1. Accessed January 4, 2014.

13. Kämmerer PW, Toyoshima T, Eletr S, Kämmerer P, Kuhr K, Al-Nawas B and Brieger J: Single nucleotide polymorphisms of the vascular endothelial growth factor gene associated with incidence of oral squamous cell carcinoma. J Oral Pathol Med 39: 786-792, 2010.
14. Wang YH, Yeh SD, Wu MM, et al: Comparing the joint effect of arsenic exposure, cigarette smoking and risk genotypes of vascular endothelial growth factor on upper urinary tract urothelial carcinoma and bladder cancer. J Hazard Mater 262: 1139-1146, 2013.

15. Fearon IM, Acheampong DO and Bishop E: Modification of smoke toxicant yields alters the effects of cigarette smoke extracts on endothelial migration: an in vitro study using a cardiovascular disease model. Int J Toxicol 31: 572-583, 2012.

16. Chen Y, Dawes PT and Mattey DL: Polymorphism in the vascular endothelial growth factor A (VEGFA) gene is associated with serum VEGF-A level and disease activity in rheumatoid arthritis: differential effect of cigarette smoking. Cytokine 58: 390-397, 2012.

17. Chen Y, Dawes PT, Packham JC and Mattey DL: Interaction between smoking and polymorphism in the promoter region of the VEGFA gene is associated with ischemic heart disease and myocardial infarction in rheumatoid arthritis. J Rheumatol 38: 802-809, 2011.

18. Zhai R, Liu G, Asomaning K, et al: Genetic polymorphisms of VEGF, interactions with cigarette smoking exposure and esophageal adenocarcinoma risk. Carcinogenesis 29: 2330-2334, 2008.

19. Kämmerer PW, Koch FP, Schiegnitz E, Kumar VV, Berres M, Toyoshima T, Al-Nawas B and Brieger J: Associations between single-nucleotide polymorphisms of the VEGF gene and long-term prognosis of oral squamous cell carcinoma. J Oral Pathol Med 42: 374-381, 2013.

20. Supic G, Jovic N, Zeljic K, Kozomara R and Magic Z: Association of VEGF-A genetic polymorphisms with cancer risk and survival in advanced-stage oral squamous cell carcinoma patients. Oral Oncol 48: 1171-1177, 2012.

21. Ku KT, Wan L, Peng HC, Tsai MH, Tsai CH and Tsai FJ: Vascular endothelial growth factor gene-460 C/T polymorphism is a biomarker for oral cancer. Oral Oncol 41: 497-502, 2005.

22. Lin L, Cao K, Chen W, Pan X and Zhao H: Four common vascular endothelial growth factor polymorphisms (-2578C $>$ A, $-460 \mathrm{C}>\mathrm{T},+936 \mathrm{C}>\mathrm{T}$, and $+405 \mathrm{G}>\mathrm{C}$ ) in susceptibility to lung cancer: a meta-analysis. PLoS One 8: e75123, 2013.

23. Cheng CY, Chang CS, Liu CJ and Kao SY: Vascular endothelial growth factor $936 \mathrm{C} / \mathrm{T}$ polymorphism is associated with vascular invasion in oral squamous cell carcinoma. Oral Surg Oral Med Oral Pathol Oral Radiol Endod 106: 79-84, 2008.

24. Lin YC, Yeh CJ, Wang LH, Lee CW and Chen CH: The effect of $\mathrm{CCND} 1+870 \mathrm{~A}>\mathrm{G}$ and $\mathrm{VEGF}+936 \mathrm{C}>\mathrm{T}$ polymorphisms on oral cancer development and disease-free survival in a Taiwan population. Oral Oncol 48: 535-540, 2012.

25. Borase AP, Ganvir SM, Hazarey VK, Gosavi SR, Mohatta AA and Singh J: Estimation of vascular endothelial growth factor gene $-460 \mathrm{C} / \mathrm{T}$ polymorphism as a biomarker in oral squamous cell carcinoma patients from the Indian subcontinent. J Investig Clin Dent: Jul 22, 2014 (Epub ahead of print). doi: 10.1111/jicd.12103.

26. Krippl P, Langsenlehner U, Renner W, Yazdani-Biuki B, Wolf G, Wascher TC, Paulweber B, Haas J and Samonigg H: A common $936 \mathrm{C} / \mathrm{T}$ gene polymorphism of vascular endothelial growth factor is associated with decreased breast cancer risk. Int J Cancer 106: 468-471, 2003.

27. Jin Q,Hemminki K, Enquist K, et al: Vascular endothelial growth factor polymorphisms in relation to breast cancer development and prognosis. Clin Cancer Res 11: 3647-3653, 2005.

28. McCarron SL, Edwards S, Evans PR, et al: Influence of cytokine gene polymorphisms on the development of prostate cancer. Cancer Res 62: 3369-3372, 2002.

29. Howell WM, Bateman AC, Turner SJ, Collins A and Theaker JM: Influence of vascular endothelial growth factor single nucleotide polymorphisms on tumour development in cutaneous malignant melanoma. Genes Immun 3: 229-232, 2002.

30. Egleton RD, Brown KC and Dasgupta P: Angiogenic activity of nicotinic acetylcholine receptors: implications in tobacco-related vascular diseases. Pharmacol Ther 121: 205-223, 2009.

31. Michaud S, Menard C, Guy LG, Gennaro G and Rivard A: Inhibition of hypoxia-induced angiogenesis by cigarette smoke exposure: impairment of the HIF-1alpha/VEGF pathway. FASEB J 17: 1150-1152, 2003 . 